\title{
TBC-CEA-Contaminated W/ BVDV
}

National Cancer Institute

\section{Source}

National Cancer Institute. TBC-CEA-Contaminated WI BVDV. NCI Thesaurus. Code C29476.

A cancer vaccine consisting of a recombinant vector encoding the tumor-associated carcinoembryonic antigen (CEA) that is contaminated with bovine viral diarrhea virus (BVDV). The carcinoembryonic antigen (CEA) is a prevalent tumor marker expressed by a number of different cancers such as colorectal, breast, lung and ovarian carcinomas; vaccination with vaccinia virus genetically eng ineered to express CEA may generate antitumoral T-cell responses. BVDV is an RNA pestivirus that may contaminate vaccines due to its presence in fetal calf serum used as a growth supplement in the tissue culture of mammalian cells used in vaccine production. ( $\mathrm{NClO4})$ 